\title{
Advances in Preventive Therapy for Estrogen-Receptor-Negative Breast Cancer
}

\author{
Beate C. Litzenburger • Powel H. Brown
}

Published online: 25 March 2014

(C) The Author(s) 2014. This article is published with open access at Springerlink.com

\begin{abstract}
Preventing breast cancer is an effective strategy for reducing breast cancer deaths. The purpose of chemoprevention (also termed preventive therapy) is to reduce cancer incidence by use of natural, synthetic, or biological agents. The efficacy of tamoxifen, raloxifene, and exemestane as preventive therapy against estrogen-receptor (ER)-positive breast cancer is well established for women at increased risk for breast cancer. However, because breast cancer is a heterogeneous disease, distinct preventive approaches may be required for effective prevention of each subtype. Current research is, therefore, focused on identifying alternative mechanisms by which biologically active compounds can reduce the risk of all breast cancer subtypes including ER-negative breast cancer. Promising agents are currently being developed for prevention of HER2-positive and triple-negative breast cancer (TNBC) and include inhibitors of the ErbB family receptors, COX-2 inhibitors, metformin, retinoids, statins, poly(ADP-ribose) polymerase inhibitors, and natural compounds. This review focuses on recent progress in research to develop more effective preventive agents, in particular for prevention of ER-negative breast cancer.
\end{abstract}

Keywords Breast cancer · Prevention .

Estrogen receptor-negative breast cancer .

Triple-negative breast cancer

B. C. Litzenburger · P. H. Brown $(\bowtie)$

Department of Clinical Cancer Prevention, The University of Texas

MD Anderson Cancer Center, 1155 Herman P. Pressler, Unit 1360,

Houston, TX 77030, USA

e-mail: phbrown@mdanderson.org

B. C. Litzenburger

e-mail: bclitzenburger@mdanderson.org

\section{Introduction}

Given the global increase in cancer incidence with its associated morbidity, mortality, and enormous treatment costs, there is increasing interest in strategies for disease prevention. Breast cancer is the most common form of cancer among women worldwide, with an estimated 232,340 new cases among US women in 2013 alone [1]. In the US the incidence has been stable over the last decade, although increasing almost everywhere throughout the world. Although breast cancer mortality is declining [1,2], preventing breast cancer is the most effective way of reducing breast cancer death. Primary prevention focuses on preventing cancer from developing or delaying the development of a malignancy. Prevention strategies encompass avoidance of known carcinogens (e.g. benzene), promotion of behavioral strategies to reduce risk through diet, exercise, limited alcohol consumption, and no tobacco use. For individuals with a particularly high risk of breast cancer, management includes genetic screening, early detection by use of mammography and breast MRI, use of preventive medications, and such surgical strategies as bilateral mastectomy.

Prevention of either the initial phases of carcinogenesis or the progression of premalignant cells to invasive disease, thereby reducing the risk of cancer, can be achieved by pharmacological means, commonly referred to as chemoprevention (also termed preventive therapy). The purpose of chemoprevention is to reduce cancer incidence by use of natural, synthetic, or biological agents. The value of this approach has been demonstrated in breast cancer prevention trials which have primarily focused on endocrine intervention by use of selective estrogen receptor modulators (SERMs; for example tamoxifen) and aromatase inhibitors (AIs; for example exemestane) (comprehensively reviewed elsewhere [3]).

Because breast cancer includes both estrogen-receptorpositive (ER-positive) and estrogen-receptor-negative (ER- 
negative) subtypes, distinct chemopreventive approaches may be required for effective prevention of each subtype. Promising approaches to prevention of ER-negative breast cancer include targeting molecules critical for the growth and progression of ER-negative tumors, for example inhibitors of the ErbB family of receptors, cyclooxygenase-2 (COX2) inhibitors, metformin, retinoids, statins, poly(ADP-ribose) polymerase, natural compounds, and others (Fig. 1).

Studies leading to successful FDA approval of antiestrogenic drugs for prevention of ER-positive breast cancer among high-risk women are reviewed briefly below. However, these drugs do not reduce the risk of ER-negative breast cancer, which accounts for 20-30\% of breast cancers. Therefore, we also review chemopreventive approaches to reducing the risk of ER-negative breast cancer.

\section{Subtypes of Breast Cancer}

The classical breast cancer subtypes are based on assessment of clinical and pathological factors, for example ER, progesterone receptor (PR), or HER2 status, tumor grade, tumor size, and the presence or absence of lymph node metastasis. However, microarray-based gene-expression studies have led to the identification of molecular subtypes (basal-like, HER2-enriched, luminal, and normal breastlike) with distinctly different survival and treatment response [4, 5]. Luminal tumors are ER and PR-positive whereas HER2-positive tumors arise from overexpression or amplification of the EGFR family of receptor tyrosine kinases, particularly HER2 (also called ErbB2, neu). HER2 overexpression is present in approximately 20-30\% of all human breast tumors, particularly those that are ERnegative [6]. Triple-negative breast cancer (TNBC) is characterized by lack of expression of ER, PR, and HER2 and accounts for approximately 15-20\% of all breast cancer diagnoses. TNBC is molecularly a heterogeneous disease. Most basal-like breast cancers $(\sim 80 \%)$ are of the triplenegative phenotype. More recently, TNBC has been divided into six distinct subtypes:

1. immunomodulatory;

2. mesenchymal;

3. mesenchymal stem-like;

4. luminal androgen receptor;

5. basal-like 1; and

6. basal-like 2 [7].
Fig. 1 Molecular targets for breast cancer chemoprevention. Solid lines indicate drugs currently used in preclinical or clinical chemopreventive studies whereas dotted lines indicate promising drugs for future chemopreventive studies. mTORC1, mammalian target of rapamycin complex 1 composed of mTOR, Raptor, MLST8, PRAS40, and DEPTOR [121]; mTORC2, mammalian target of rapamycin complex 2 composed of mTOR, RICTOR, mLST8 and mSIN1 [122].

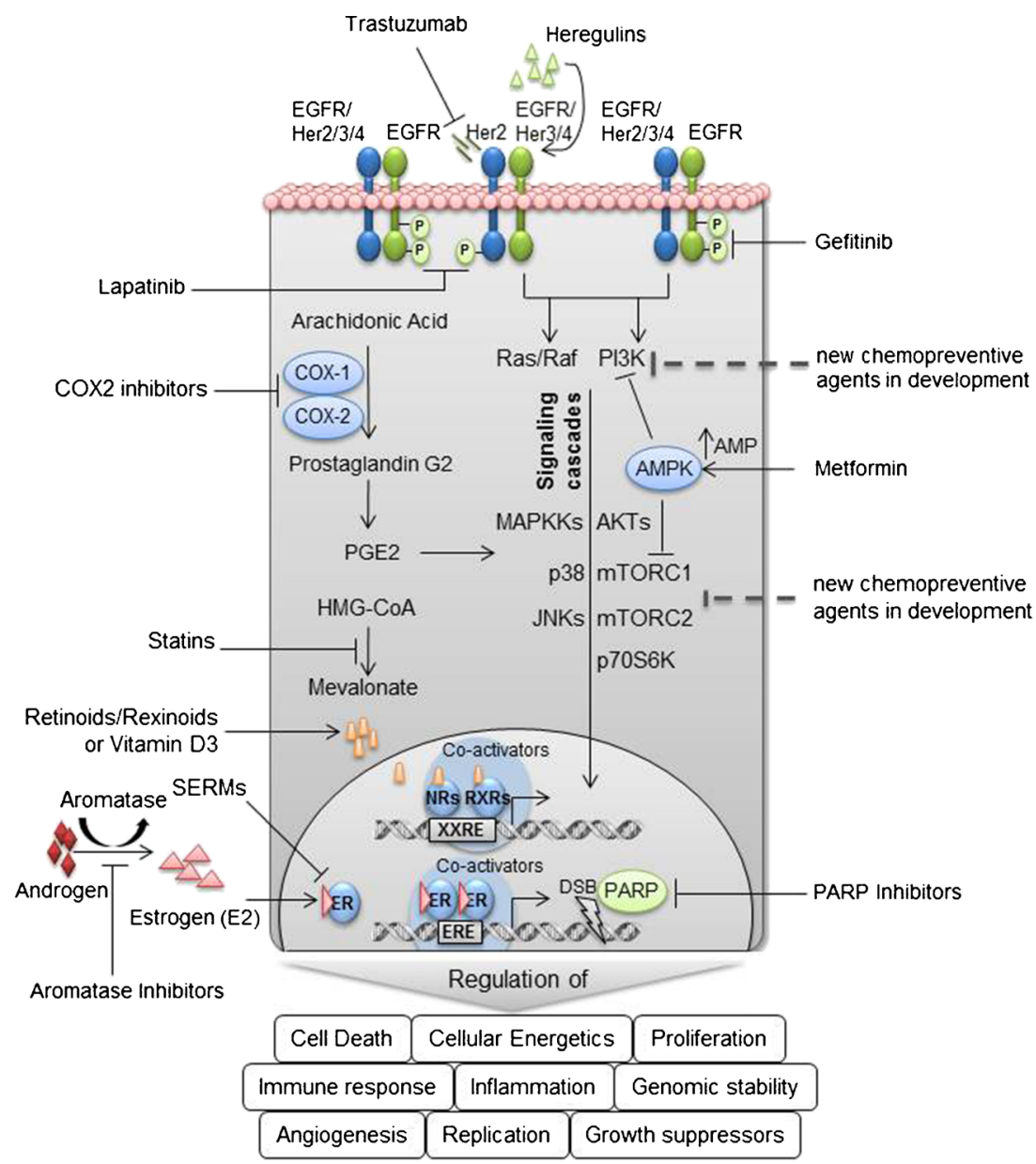


Therefore, the development of effective preventive agents suppressing the development of TNBC remains a challenge, because of the heterogeneity of the disease.

\section{Prevention of ER-Positive Breast Cancers}

ER and its ligand estrogen are key regulators in breast cancer carcinogenesis, and modulation of the receptor or reduction of estrogen are strategies for reduction of breast cancer risk. Clinical studies testing SERMs, for example tamoxifen, or AIs, for example anastrozole, for treatment of early breast cancer laid the foundation for breast cancer prevention in the future.

The National Surgical Adjuvant Breast and Bowel Project (NSABP) BCPT (also known as P-1) trial demonstrated that tamoxifen reduced the risk of invasive breast cancer by $49 \%$ versus placebo among women at risk [8]. The STAR trial demonstrated that raloxifene was as effective as tamoxifen, and reduced breast cancer risk in postmenopausal women by approximately $50 \%$ [9]. The results of the P-1 and STAR trials led to FDA approval of tamoxifen or raloxifene for use for breast cancer prevention among high-risk women. More recently, the 81-month follow-up study demonstrated that after stopping drug treatments after five years the cancerpreventive effect of tamoxifen persisted whereas the cancerpreventive effect of raloxifene diminished over time. Raloxifene retained only $76 \%$ of the effectiveness of tamoxifen at prevention of invasive breast cancer [10]. However, raloxifene was generally less toxic than tamoxifen, which is of particular interest for high-risk postmenopausal women with intact uterus who are concerned about the risk of hot flushes, thromboembolic side effects, and endometrial cancer, whereas tamoxifen may be preferred for a high-risk postmenopausal woman without a uterus, and for premenopausal women [11].

Clinical trials of AIs as adjuvant therapy demonstrated their cancer-preventive potential, because they effectively prevent breast cancer recurrence $[12,13]$ and the development of second primary contralateral tumors [12]. The NCIC-MAP.3 trial tested the aromatase inhibitor exemestane versus placebo among postmenopausal high risk women for up to five years of treatment [14]. In this trial, exemestane reduced the incidence of invasive breast cancer by $65 \%$ and the incidence of ER-positive invasive breast cancer by $73 \%$. Adverse events, for example endometrial cancers and thromboembolic events, which are usually associated with tamoxifen treatment, were not reported. On the other hand, exemestane is associated with hot flushes and bone pain, and increases the risk of bone fracture [14]. The IBIS-II trial tested the cancer-preventive effect of another AI, anastrozole, among postmenopausal women at risk for breast cancer. The results of this trial, in which women were treated with $1 \mathrm{mg}$ oral anastrozole or placebo every day for five years, were recently reported
[15]. Anastrozole reduced the incidence of breast cancer by $53 \%$ among high-risk postmenopausal women [15].

Although AIs are not yet FDA-approved for breast cancer prevention, these drugs are already being used off-label for this purpose. The success of SERMS and AIs demonstrates that preventive therapy for breast cancer is possible.

\section{Prevention of HER2-Positive Breast Cancer}

Several different ErbB family receptor inhibitors are FDAapproved for clinical use. The monoclonal antibodies cetuximab, trastuzumab, and pertuzumab are directed against the extracellular domain of their target receptor proteins and prevent receptor interaction with growth factor and/or dimerization with other receptors whereas the small-molecule inhibitors lapatinib, gefitinib, and erlotinib interfere with the kinase activity of their target proteins (Fig. 1) [16]. Given the activity of these drugs in cancer treatment research is now focused on investigating in particular oral HER2 and EGFR receptor tyrosine kinase inhibitors in preclinical and early clinical trials as breast cancer-preventive drugs.

In preclinical mouse models our group has shown that treatment with gefitinib, an EGFR kinase inhibitor, delayed the development of spontaneous ER-negative, HER2-positive mammary tumors in the MMTV-ErbB2 transgenic mouse model [17] (median time to tumor formation in the control group 230 days versus 310 days in the high-dose gefitinib group, $p<0.001$ ) (Table 1). Furthermore, gefitinib reduces proliferation and tumor multiplicity (Table 1) [18, 19]. Likewise, Lapatinib, a dual EGFR and ErbB2 receptor tyrosine kinases inhibitor, or vehicle was administered long-term to MMTV-ErbB2 transgenic mice before the development of tumors. Lapatinib inhibited the formation of premalignant lesions in the mammary gland and reduced ER-negative and HER2-positive tumor development by $69 \%$ (Table 1) [20].

Lapatinib was further investigated in clinical trials. In a phase II trial lapatinib (1,500 mg once a day) or placebo was investigated for treatment of 60 women with HER2-positive ductal carcinoma in situ (DCIS) for three weeks before surgical resection [21]. Primary endpoint results revealed reduced proliferation of breast epithelial cells, adjacent ductal intraepithelial neoplasia, and distant ductal hyperplasia (indicated by immunohistochemical staining for KI67) (Table 2) [21]. Another similar trial among women with HER2 or EGFR-positive DCIS is currently testing the effect of lapatinib $\left(1000 \mathrm{mg}\right.$ day $\left.^{-1}\right)$ versus placebo for two to six weeks before surgical excision. The primary objective is to determine the rate of proliferation of DCIS breast cancer cells measured by immunohistochemical staining for Ki67. Secondary endpoints include investigation of whether lapatinib affects the incidence of DCIS observed at time of surgical excision (Table 2).

Treatment of HER2-positive DCIS with trastuzumab, a monoclonal antibody against HER2, was tested in a phase II 


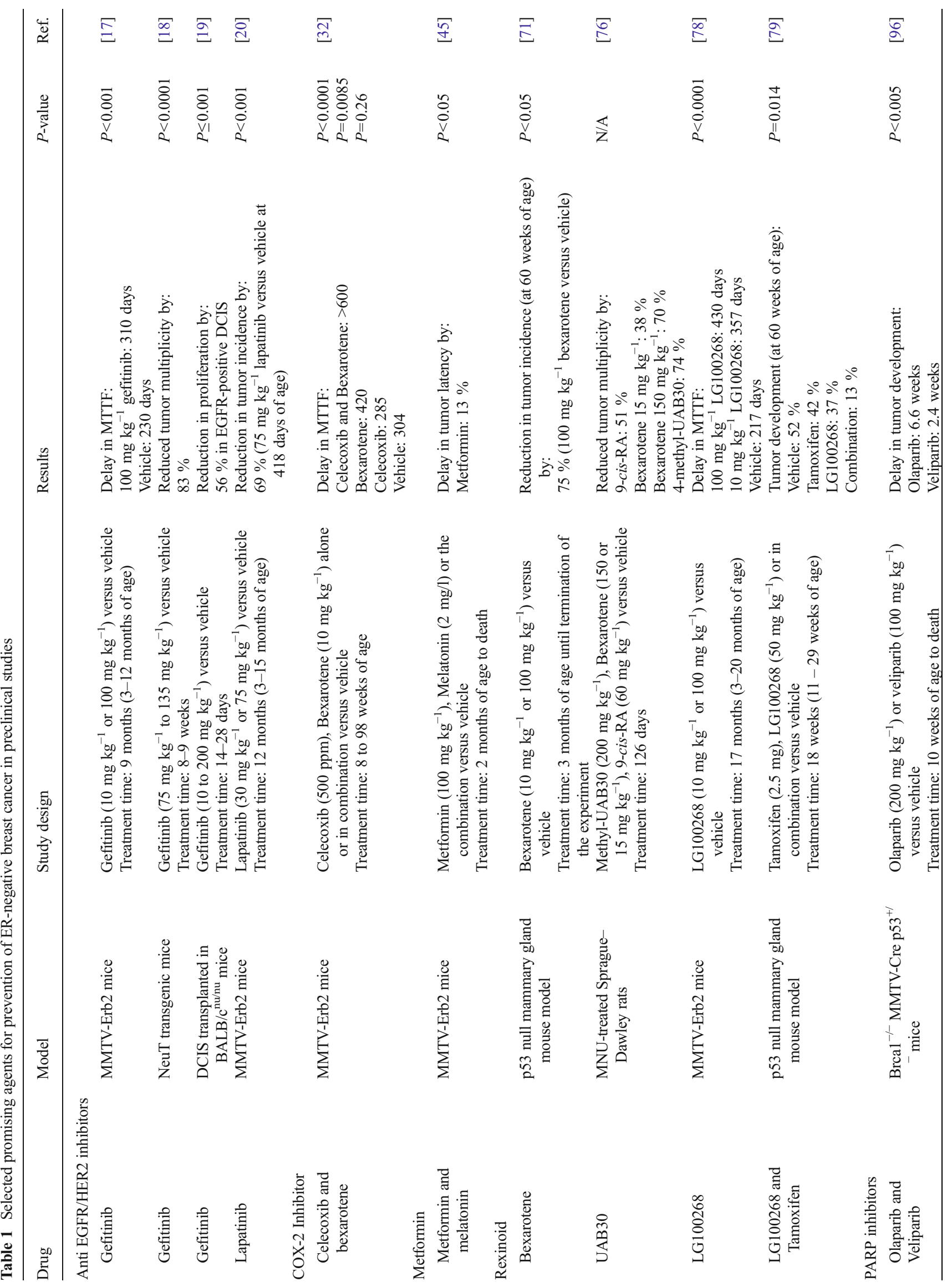


trial in a neoadjuvant setting. Preoperative single-dose monotherapy with trastuzumab resulted in an immunologic response (increased antibody-dependent cell-mediated cytotoxicity) with no association in histologic, antiproliferative, or apoptotic changes (Table 2) [22]. In an ongoing phase III NSABP-43 trial the effect of trastuzumab is being assessed in women with HER2-positive DCIS after excisional surgery given concurrently with radiation or radiation alone. The primary objective is to determine whether trastuzumab prevents subsequent recurrence of ipsilateral breast cancer, ipsilateral skin cancer, or ipsilateral DCIS. One of the secondary objectives is to determine whether trastuzumab has a preventive effect in prolonging invasive or DCIS disease-free survival (Table 2).

In addition to FDA-approved HER2/EGFR inhibitors, such alternative approaches as use of Her-2/neu vaccines to manipulate the immune system with long-lasting anti-tumor effects are under investigation. Several systems have been developed to deliver tumor-associated antigens into the body, for example whole tumor cell vaccines, dendritic cell vaccines, viral vector vaccines, and peptide vaccines, the last being the focus of clinical investigations among high-risk women for prevention of HER2-positive breast cancer. The most studied HER2derived peptide in clinical trials is E75 (NeuVax, HER2/neu 369-377), an immunogenic HLA class-I peptide that stimulates cytotoxic T lymphocytes. Results from phase II studies suggest that E75, in particular when administered in the adjuvant setting, prevents disease recurrence among selected highrisk patients [23, 24]. The first phase III clinical trial, called the PRESENT trial, will determine the efficacy and safety of E75 vaccine and evaluate and compare disease-free survival (DFS) among E75 vaccinated patients and control patients. Another ongoing phase II study will investigate the combination of immunotherapy with E75 and trastuzumab to prevent recurrence among high-risk HER2-positive breast cancer patients who are disease-free after standard of care therapy.

\section{Preventive Agents for ER-Negative Breast Cancer Including TNBC}

NSAIDs, Aspirin, and COX-2 Inhibitors

Increasing epidemiological, experimental, and clinical studies have demonstrated that nonsteroidal anti-inflammatory drugs (NSAIDs) have a preventive effect on the development of some malignancies including breast cancer. NSAIDs inhibit cyclooxygenase (COX), for which two isoforms, COX-1 and COX-2, have been described. COX-1 is constitutively produced in most cells whereas COX-2 is induced by mitotic signals and pro-inflammatory stimuli [25]. NSAIDs impair the transformation of arachidonic acid to prostaglandins (Fig. 1), prostacyclin, and thromboxanes. COX-2 is overexpressed in 


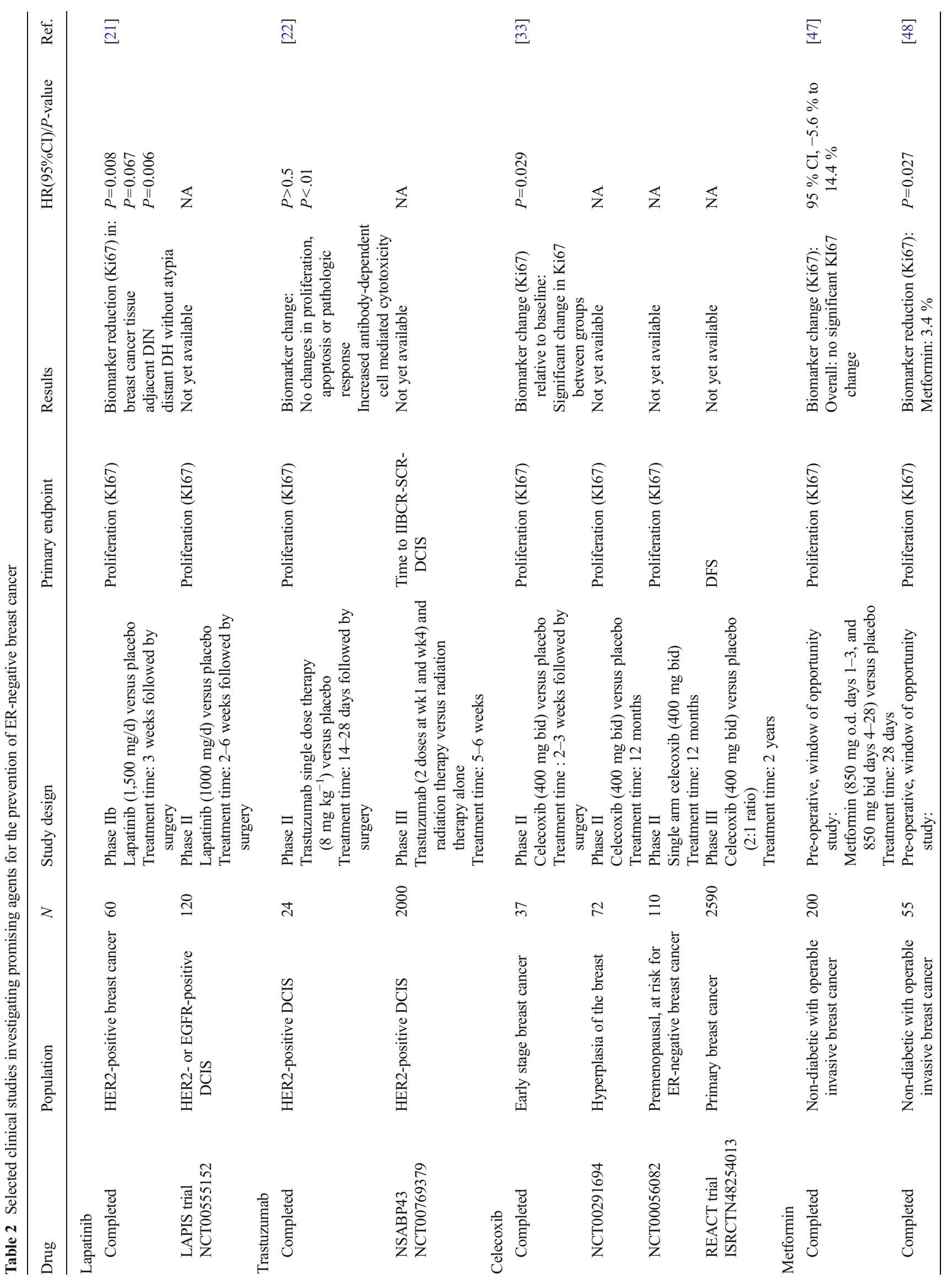




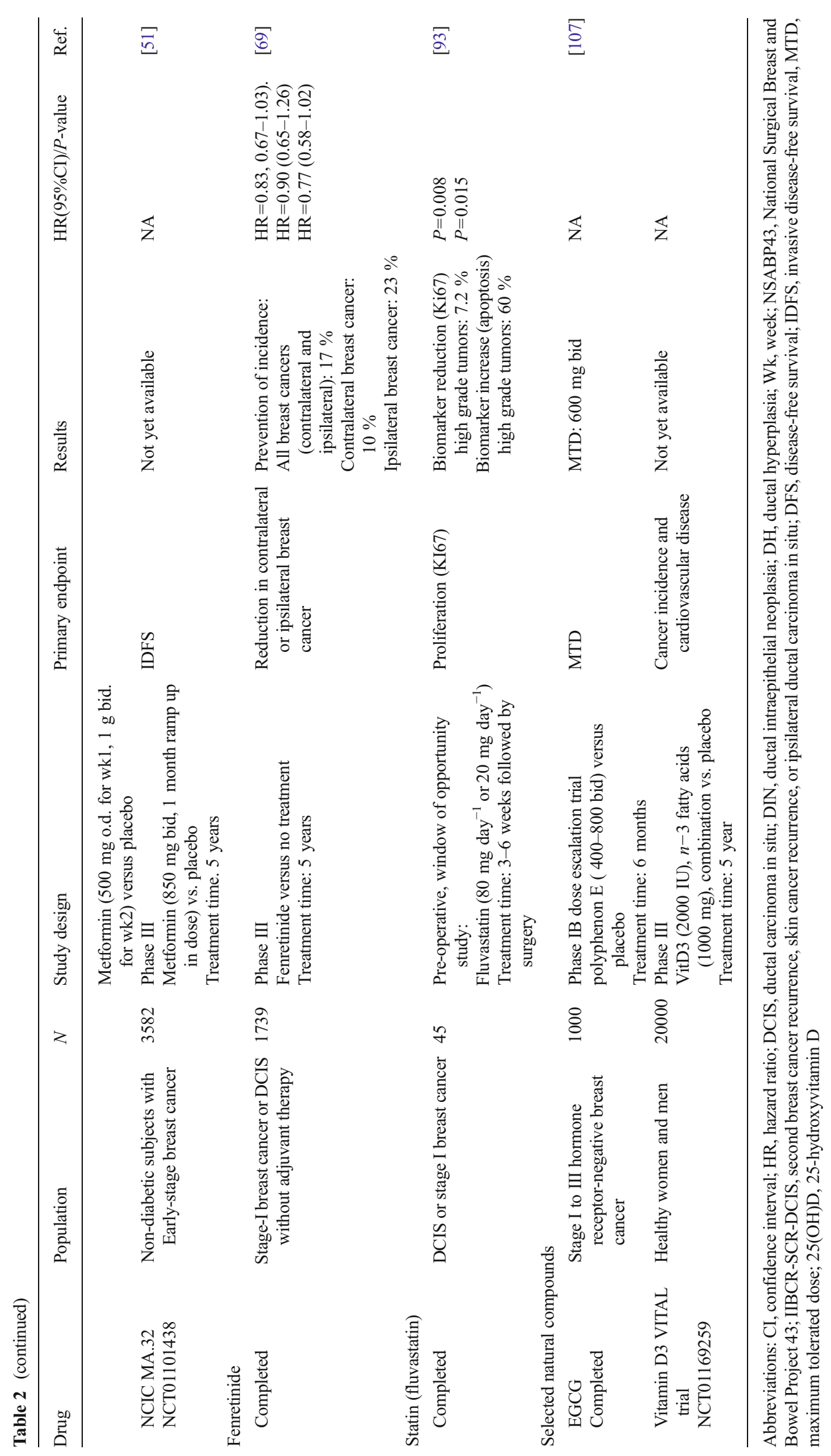


invasive breast cancer, and in DCIS and adjacent tissue, suggesting COX-2 is an important driver of mammary tumorigenesis [26].

Most traditional NSAIDs, for example aspirin, are nonselective inhibitors of both COX-1 and COX-2. Randomized studies have identified reduced cancer risk (e.g., lung, colon, breast) associated with long-term use of aspirin [27]. A metaanalysis showed that long-term aspirin intake is associated with a $10 \%$ reduction in risk of breast cancer [28]. Extended follow-up revealed overall cancer mortality was reduced by approximately $20 \%$ among people with regular intake of aspirin, with the greatest benefit seen in deaths from adenocarcinoma (36 \% reduction) [27].

The selective COX-2 inhibitors celecoxib (Celebrex), rofecoxib (Vioxx), and valdecoxib (Bextra) have received approval from the FDA in the US for treatment of pain; rofecoxib and valdecoxib were, however, withdrawn worldwide by the manufacturer after an increased number of cardiovascular events was seen in placebo-controlled trials. Therefore, subsequent research has focused on investigating the cancer-preventive effectiveness of celecoxib in preclinical and clinical studies.

In preclinical studies treatment with celecoxib reduced mammary tumor incidence among treated mice [29, 30]. However, one study using the same mouse model showed that celecoxib was unable to prevent tumor development [31]. Our group showed celecoxib alone was ineffective but coadministration of celecoxib and bexarotene, a rexinoid, substantially delayed tumor development (Table 1) [32].

Recently, a phase II biomarker trial has demonstrated that celecoxib reduced proliferation in primary breast cancer tissues [33]. The first phase III clinical trial, called REACT, assessing the disease-free survival benefit of two years of celecoxib treatment among women with resected primary breast cancer is currently in progress (Table 2).

Although COX inhibitors have a significant chemopreventive effect on breast cancer risk, further clinical trials are needed. Moreover, concerns about rare serious toxicity, cardiovascular toxicity associated with COX-2 inhibitors, and other known potential side effects of treatment with NSAIDS, for example gastrointestinal bleeding and perforation, should be taken into account before routine implementation of NSAIDS as chemoprevention for breast cancer. To advance this field, new less toxic drugs targeting the COX2 pathway will need to be developed.

\section{Metformin}

Metformin (1,1-dimethylbiguanide) is the most widely used first-line therapy of choice for type 2 diabetes mellitus. The primary target of metformin is AMPK in the mitochondria $[34,35]$. Upon disruption of mitochondrial complex I, AMP/ ATP and ADP/ATP ratios are increased which activates AMPK [34, 35] (Fig. 1). AMPK activation controls many metabolic processes, including fatty acid synthesis, gluconeogenesis in the liver, and glucose uptake in muscle (reviewed elsewhere [36]). However, the molecular mechanism of the preventive effect of metformin is still not understood. It is suggested that reduced insulin levels on treatment with metformin result in reduction of cell growth, thereby reducing tumorigenesis [37].

Epidemiological studies recently confirmed an association between type 2 diabetes and breast cancer risk, predominantly among postmenopausal women [38]. Moreover, other retrospective studies have demonstrated that metformin, in particular, reduces the risk of breast cancer compared with other antidiabetic therapy (e.g., insulin, alpha-glucosidase inhibitors, prandial glucose regulators, sulfonylureas, thiazolidinediones) [39-44]. In laboratory studies, metformin inhibits mammary tumor growth (Table 1) [45] and selectively targets tumor-initiating cells in this mouse model [46].

Because of these promising epidemiologic and preclinical data, several phase I and II trials were conducted to investigate its breast cancer-preventive effects [47-49]. Most of these studies were neoadjuvant "window of opportunity" studies among women with operable breast cancer and investigated a variety of biomarker changes after metformin administration (Table 2). Metformin reduced proliferation (KI67) and increased apoptosis (TUNEL staining) in invasive tumor tissue $[49,50]$. Phase II and III clinical trials are currently in progress to further elucidate the cancer-preventive effect of metformin [51-55]. One important currently ongoing phase III study is the NCIC-MA.32 trial testing five years of metformin or placebo among women with early-stage breast cancer [51]. The primary outcome is invasive disease-free survival, with overall survival and contralateral breast cancer incidence as secondary endpoints (Table 2).

The results of these clinical trials will determine whether metformin will be useful for the prevention of breast cancer.

\section{Retinoids}

Evidence from in-vitro studies suggest that retinoids control various signaling mechanisms irrespective of the ER/PR status of the cell, which makes them particularly promising drugs for prevention of ER-negative breast cancer. Retinoids are vitamin A analogues that regulate gene expression by binding to nuclear hormone receptors, including retinoic acid receptors (RARs) and retinoid X receptors (RXRs) [56]. Retinoids, for example all-trans-retinoic acid (ATRA), alitretinoin (9-cisRA), and isotretinoin (13-cis-RA), can activate RAR and RXR, which heterodimerize and bind to the DNA on RA response elements to induce activation of genes involved in cellular proliferation, differentiation, and apoptosis [56].

Retinoids have been successfully used for prevention and treatment of cancers [57] and a variety of preclinical studies using mouse and rat models have demonstrated reduced 
mammary tumorigenesis because of the cancer-preventive effect of retinoids [58-60]. Preclinical studies also elucidated specific retinoid-mediated mechanisms of the cancerpreventive effect; these include:

- down-regulation of expression of COX2 and cyclin D1 [61];

- inhibition of AP1 transcription factor activity [62, 63];

- induction of cell cycle arrest at G1 [64, 65]; and

- overexpression of IGF binding proteins (IGF-BPs) 3 and 6 [63], RAR-beta [63] and TGF-beta [66].

One of the first chemoprevention trials among humans showed that 13-cis-RA prevented second primary tumors among head and neck patients [67]; for chemoprevention, however, the toxicity associated with 13-cis-RA treatment is not acceptable. Similarly, toxicity associated with 9-cis-RA treatment prevented further development of this agent as a standard chemopreventive drug [60,67].

The synthetic retinoic acid, fenretinide, has been widely studied in clinical trials of chemoprevention, because of its favorable toxicity profile compared with the previously mentioned retinoids. In a phase III trial women with breast cancer were randomly assigned to receive no treatment or oral fenretinide $(200 \mathrm{mg})$ daily for five years [68]. After a median follow-up of eight years, fenretinide treatment did not reduce the incidence of second breast cancers overall; when given to premenopausal women, however, fenretinide resulted in significant (38\%) reduction of the risk of second breast cancers (Table 2) $[68,69]$.

\section{Rexinoids}

Synthetic "rexinoids" (e.g. bexarotene and LG100268) activate RXR without activating RAR nuclear receptors [70-73]. Bexarotene is FDA-approved for the treatment of cutaneous Tcell lymphoma; it has been tested for treatment of advanced breast cancer but was not effective as a single agent [74]. Our laboratory has previously shown that bexarotene can prevent ER-negative/HER2 positive mammary tumors in preclinical mouse models (Table 1) [73]. A breast cancer prevention trial of bexarotene among women at genetic risk showed that it reduced proliferation markers (Ki67, Cyclin D1) in breast tissues [75]. However, as with 13-cis-RA and 9-cis-RA, bexarotene had significant side effects, for example hypertriglyceridemia, which was reversible upon stopping the drug [75].

9cUAB30 is a synthetic analog of 9-cis-RA with little or no RAR-binding activity compared with 9-cis- RA and other retinoids [76]. Preclinical animal studies proved the chemopreventive activity of 9cUAB30 in reduction of mammary cancers (Table 1) [76, 77]. A first study among humans recently demonstrated a favorable toxicity and pharmacokinetic profile of 9cUAB30, and a phase I dose-escalation study is currently in progress.
Our laboratory has previously shown that the rexinoid LG100268 can prevent ER-negative/HER2 positive mammary tumors in preclinical mouse models [78] and delay TNBC development [79]. Moreover, combination therapy using LG100268 and a synthetic triterpenoid, CDDO-methyl amide, synergistically suppressed ER-negative/HER2 positive mammary tumors (Table 1) [70]. Future preclinical and clinical studies are needed to determine the future of retinoids and rexinoids as cancer-preventive agents. Other approaches, for example combination treatments may be a promising new strategy to reduce ER-negative breast cancer incidence.

\section{Statins}

Statins inhibit 3-hydroxy-3-methyl-glutaryl-coenzyme A (HMG-CoA) reductase, which reduces the intracellular biosynthesis of cholesterol by reversibly inhibiting the conversion of HMG-CoA to mevalonate (Fig. 1) [80]. These lipidlowering drugs (for example atorvastatin, cerivastatin, fluvastatin, lovastatin, simvastatin, and pravastatin) are commonly used to treat hypercholesterolemia, and thereby reduce the risk of cardiovascular diseases. Preclinical, clinical, and epidemiologic studies provide a rationale for evaluating lipophilic statins for breast cancer prevention [80-83]. Results from these studies are conflicting, however, resulting in inconsistency in the relationship between statin use and reduced incidence of breast cancer.

A decrease in risk of many types of cancer, including breast cancer, among statin users was observed in many studies [81, 84-88]. Conversely, two meta-analyses concluded that statin use and long-term statin use did not significantly affect breast cancer risk $[89,90]$. A recently conducted study revealed no association of lipid-lowering drug use with reduced risk of breast cancer recurrence and breast cancer-specific mortality [91].

To investigate the biological effect of lipophilic statins in the prevention of breast cancer several biomarker modulation trials have been initiated [92, 93]. After short-term statin treatment of women with high-grade (DCIS or stage 1) breast cancer, proliferation was reduced and apoptosis increased (Table 2) [93]. However, another biomarker modulation trial of lovastatin among women with increased risk of breast cancer did not show any significant breast duct cytology changes after lovastatin therapy [94].

In the future, it will be necessary to conduct clinical trials among high-risk populations, in particular women at high risk of TNBC, to determine whether statins will be useful as preventive therapy.

\section{PARP Inhibitors}

Poly(ADP-ribose) polymerases, particularly PARP1, are multifunctional enzymes best known for their repair of breaks in single-strand DNA. Inhibition of PARP-1 is a promising 
approach for targeted prevention of breast cancer, especially among women with deleterious BRCA mutations [95]. Several PARP inhibitors, for example iniparib (BSI-201), olaparib (AZD2281), rucaparib (AG014699), veliparib (ABT-888), and BMN-673, are currently in clinical development as cancer therapeutics for breast and ovarian cancer [95]. However, limited data exists on studies testing the efficacy of PARP inhibitors as a prevention agent. A recent preclinical study by Liby and Sporn demonstrated that olaparib $\left(200 \mathrm{mg} \mathrm{kg}^{-1}\right.$ diet $)$ or veliparib (100 $\mathrm{mg} \mathrm{kg}^{-1}$ diet) significantly delayed tumor development in BRCA1-deficient mice (Table 1) [96]. PARP inhibitors have not yet been tested for chemoprevention in clinical or biomarker modulation trials. However, PARP inhibitors may be found to be useful for cancer prevention in the future, considering approximately 55 to $65 \%$ of BRCA1 mutation carriers will develop breast cancer by age 70 years [97].

\section{Other Promising Agents}

Novel targeted drugs with demonstrated efficacy for treatment of breast cancer may also be useful for prevention of breast cancer. IGF-pathway inhibitors, for example cixutumumab or figitumumab, have been effective in the treatment of both ERpositive and ER-negative breast cancer [98]. However, little progress has been made in determining the usefulness of these drugs as preventive therapy, partly because of their known toxicity, for example hyperglycemia. PI3K/AKT/mTOR signaling is critical for regulation of cell growth and cell survival and is thus important in tumorigenesis [99]. mTOR, a serinethreonine kinase, acts as a downstream effector of the PI3K/AKT signaling pathway and phosphorylates multiple downstream kinases [100]. mTOR inhibitors (for example rapamycin, everolimus, sirolimus, and temsirolimus) may be useful as cancer-prevention agents. Rapamycin has been used in several preclinical studies (Table 1) which demonstrated that this drug is able to reduce tumor growth in ER-negative breast tumor mouse models [101, 102]. These initial positive results are encouraging for further development of mTOR inhibitors as cancer preventive agents.

A variety of triterpenoids have chemopreventive potential in breast cancer. Natural triterpenoids are abundantly found in marine sources, for example marine sponges, sea cucumbers, or marine algae [103], and have antiproliferative, antiangiogenic, anti-inflammatory, and pro-apoptotic activity [104]. CDDO esters and CDDO-Me have been shown to delay ER-negative mammary tumor formation in animal studies (Table 1) [70, 105].

\section{Natural Compounds}

Although there is a strong interest in using more than onehundred natural compounds [106] for cancer prevention, none of these dietary agents has been shown to consistently prevent breast cancer. Some of the most promising compounds include catechins (e.g., epigallocatechin gallate (EGCG), green tea extract) [107], curcumin [108], luteolin [109], carotenoids [110], omega-3-fatty acids [111], resveratrol [112-114], soy isoflavones $[115,116]$, and vitamin D [117, 118]. For example, green tea intake has been associated with reduced incidence of breast cancer, and a recent phase IB dose-escalation trial using 400-800 mg EGCG among women with a history of stage I to III hormone receptor-negative breast cancer demonstrated that this natural compound is well tolerated [107] (Table 2). On the basis of this positive result, a phase II trial testing the cancer-preventive effect of EGCG over a one year treatment period is currently in progress among postmenopausal women with high breast density. Many vitamins, in particular Vitamin D, are currently being tested as preventive agents among women at high risk of breast cancer. The VITAL trial (vitamin D and omega-3 fatty acids) is testing the daily intake of vitamin $\mathrm{D}_{3}$ (2000 IU), omega-3 fatty acids (1000 mg), the combination, or placebo among 20,000 healthy men and women for five years [119] (Table 2). The primary outcomes are cancer incidence, cardiovascular disease, stroke, and diabetes. Although natural products are a promising alternative cancer-prevention strategy, their potential efficacy in the prevention of ER-negative and, particularly, triplenegative breast cancer will be determined in the near future.

\section{How to Select Individuals for Preventive Therapy (Risk Stratification)}

Accurate assessment of a women's breast cancer risk on the basis of known risk factors is needed to decide who might benefit most from targeted preventive therapy. In particular, targeted chemoprevention will be used for women at high risk. For example, women with HER2-positive DCIS would benefit from anti-HER2 therapy after consideration of risk versus benefit factors. To this end, statistical models have been developed to help predict breast cancer risk on the basis of known risk factors. The most frequently used is the Gail model (reviewed elsewhere [120]), although this model is not able to specify a risk for solely ER-positive or solely ER-negative breast cancer. Each of the currently available risk-prediction models has its limitations and cannot be appropriately applied to all patients. Incorporation of known biomarkers, geneexpression profiles and pharmacogenetics, susceptibility genes, and breast density is needed to accurately identify women at particularly high risk of ER-negative breast cancer.

\section{Conclusions and Future Perspective}

Because breast cancer comprises distinct subtypes, identification and development of effective and safe preventive therapy remains challenging. To successfully implement preventive 
therapy for all types of breast cancer, chemoprevention must change to personalized therapy. For example, several prevention trials among women with HER2-positive DCIS have demonstrated the potential of HER2-targeted drugs as chemopreventive agents for this subtype of breast cancer. The heterogeneous nature of TNBCs, which have multiple signaling pathways activated, necessitates multi-targeted approaches to effective TNBC prevention. Moreover, successful cancer prevention requires accurate identification of individuals at high risk of specific breast cancer subtypes. Such high-risk individuals are most likely to benefit from targeted preventive therapy.

Although many women qualify for preventive therapy, most high-risk women are not interested in using drugs for cancer prevention. This is partly because of the perception that the benefits do not outweigh the side effects. Whereas many women with cancer will tolerate side effects during their therapy, most women do not accept the same side effects of preventive therapy when healthy. To overcome this challenge, education of the public and medical community with evidence-based risk and benefit information is needed. Moreover, most preventive therapy is administered chronically for many years; other strategies, for example intermittent dosing schedules should be investigated to reduce common and rare serious side effects.

The success of breast cancer prevention research depends on molecularly targeted approaches, particularly for TNCB prevention, and the development of less toxic drugs that interrupt drivers of tumorigenesis.

Acknowledgments This work was funded by the Cancer Center Support Grant (CA16672, PHB) a Susan G. Komen Promise Grant (KG081694, PHB), a Komen SAB Grant (SAB12-00006, PHB), and a NCI R25T Grant (R25CA057730, BCL).

Authors' Contributions Literature review, writing, review and/or revision: BC Litzenburger and PH Brown

\section{Compliance with Ethics Guidelines}

Conflict of Interest Powel H. Brown is on the Scientific Advisory Board of Susan G. Komen for the Cure. Beate C. Litzenburger declares that she has no conflict of interest.

Human and Animal Rights and Informed Consent This article does not contain any studies with human or animal subjects performed by any of the authors.

Open Access This article is distributed under the terms of the Creative Commons Attribution License which permits any use, distribution, and reproduction in any medium, provided the original author(s) and the source are credited.

\section{References}

1. Siegel R, Naishadham D, Jemal A. Cancer statistics, 2013. CA Cancer J Clin. 2013;63(1):11-30.
2. Autier P, Boniol M, La Vecchia C, Vatten L, Gavin A, Hery C, et al. Disparities in breast cancer mortality trends between 30 European countries: retrospective trend analysis of WHO mortality database. BMJ. 2010;341:c3620.

3. den Hollander P, Savage MI, Brown PH. Targeted Therapy for Breast Cancer Prevention. Front Oncol. 2013;3:250.

4. Weigelt B, Reis-Filho JS. Histological and molecular types of breast cancer: is there a unifying taxonomy? Nat Rev Clin Oncol. 2009;6(12):718-30.

5. Foulkes WD, Smith IE, Reis-Filho JS. Triple-negative breast cancer. N Engl J Med. 2010;363(20):1938-48.

6. Ariga R, Zarif A, Korasick J, Reddy V, Siziopikou K, Gattuso P. Correlation of her-2/neu gene amplification with other prognostic and predictive factors in female breast carcinoma. Breast $\mathrm{J}$. 2005;11(4):278-80.

7. Lehmann BD, Bauer JA, Chen X, Sanders ME, Chakravarthy AB, Shyr Y, et al. Identification of human triple-negative breast cancer subtypes and preclinical models for selection of targeted therapies. J Clin Invest. 2011;121(7):2750-67.

8. Fisher B, Costantino JP, Wickerham DL, Redmond CK, Kavanah M, Cronin WM, et al. Tamoxifen for prevention of breast cancer: report of the National Surgical Adjuvant Breast and Bowel Project P-1 Study. J Natl Cancer Inst. 1998;90(18):1371-88.

9. Vogel V, Costantino J, Wickerham D, Cronin W, Cecchini R, Atkins $\mathrm{J}$, et al. Effects of tamoxifen vs raloxifene on the risk of developing invasive breast cancer and other disease outcomes: the NSABP Study of Tamoxifen and Raloxifene (STAR) P-2 trial. JAMA. 2006;295:2727-41.

10. Vogel VG, Costantino JP, Wickerham DL, Cronin WM, Cecchini RS, Atkins JN, et al. Update of the National Surgical Adjuvant Breast and Bowel Project Study of Tamoxifen and Raloxifene (STAR) P-2 Trial: Preventing breast cancer. Cancer Prev Res (Phila). 2010;3(6):696-706.

11. Hortobagyi GN, Brown PH. Two good choices to prevent breast cancer: great taste, less filling. Cancer Prev Res (Phila). 2010;3(6): $681-5$.

12. Dowsett M, Cuzick J, Ingle J, Coates A, Forbes J, Bliss J, et al. Meta-analysis of breast cancer outcomes in adjuvant trials of aromatase inhibitors versus tamoxifen. J Clin Oncol. 2010;28(3):509 18.

13. Cuzick J, Sestak I, Baum M, Buzdar A, Howell A, Dowsett M, et al. Effect of anastrozole and tamoxifen as adjuvant treatment for earlystage breast cancer: 10-year analysis of the ATAC trial. Lancet Oncol. 2010;11(12):1135-41.

14. Goss PE, Ingle JN, Ales-Martinez JE, Cheung AM, Chlebowski RT, Wactawski-Wende J, et al. Exemestane for breast-cancer prevention in postmenopausal women. N Engl J Med. 2011;364(25):2381-91.

15. Cuzick J, Sestak I, Forbes JF, Dowsett M, Knox J, Cawthorn S, Saunders C, Roche N, Mansel RE, von Minckwitz G et al. Anastrozole for prevention of breast cancer in high-risk postmenopausal women (IBIS-II): an international, double-blind, randomised placebo-controlled trial. Lancet 2013.

16. Hynes NE, Lane HA. ERBB receptors and cancer: the complexity of targeted inhibitors. Nat Rev Cancer. 2005;5(5):341-54.

17. Lu C, Speers C, Zhang Y, Xu X, Hill J, Steinbis E, et al. Effect of epidermal growth factor receptor inhibitor on development of estrogen receptor-negative mammary tumors. J Natl Cancer Inst. 2003;95(24):1825-33.

18. Piechocki MP, Dibbley SK, Lonardo F, Yoo GH. Gefitinib prevents cancer progression in mice expressing the activated rat HER2/neu. Int J Cancer. 2008;122(8):1722-9.

19. Chan KC, Knox WF, Gee JM, Morris J, Nicholson RI, Potten CS, et al. Effect of epidermal growth factor receptor tyrosine kinase inhibition on epithelial proliferation in normal and premalignant breast. Cancer Res. 2002;62(1):122-8. 
20. Strecker TE, Shen Q, Zhang Y, Hill JL, Li Y, Wang C, et al. Effect of lapatinib on the development of estrogen receptor-negative mammary tumors in mice. J Natl Cancer Inst. 2009;101(2):107-13.

21. Decensi A, Puntoni M, Pruneri G, Guerrieri-Gonzaga A, Lazzeroni $\mathrm{M}$, Serrano D, et al. Lapatinib activity in premalignant lesions and HER-2-positive cancer of the breast in a randomized, placebocontrolled presurgical trial. Cancer Prev Res (Phila). 2011;4(8): 1181-9.

22. Kuerer HM, Buzdar AU, Mittendorf EA, Esteva FJ, Lucci A, Vence $\mathrm{LM}$, et al. Biologic and immunologic effects of preoperative trastuzumab for ductal carcinoma in situ of the breast. Cancer. 2011;117(1):39-47.

23. Peoples GE, Gurney JM, Hueman MT, Woll MM, Ryan GB, Storrer $\mathrm{CE}$, et al. Clinical trial results of a HER2/neu (E75) vaccine to prevent recurrence in high-risk breast cancer patients. J Clin Oncol. 2005;23(30):7536-45.

24. Peoples GE, Holmes JP, Hueman MT, Mittendorf EA, Amin A, Khoo S, et al. Combined clinical trial results of a HER2/neu (E75) vaccine for the prevention of recurrence in high-risk breast cancer patients: U.S. Military Cancer Institute Clinical Trials Group Study I-01 and I-02. Clin Cancer Res. 2008;14(3):797-803.

25. Agrawal A, Fentiman IS. NSAIDs and breast cancer: a possible prevention and treatment strategy. Int J Clin Pract. 2008;62(3): 444-9.

26. Shim V, Gauthier ML, Sudilovsky D, Mantei K, Chew KL, Moore $\mathrm{DH}$, et al. Cyclooxygenase-2 expression is related to nuclear grade in ductal carcinoma in situ and is increased in its normal adjacent epithelium. Cancer Res. 2003;63(10):2347-50.

27. Rothwell PM, Fowkes FG, Belch JF, Ogawa H, Warlow CP, Meade TW. Effect of daily aspirin on long-term risk of death due to cancer: analysis of individual patient data from randomised trials. Lancet. 2011;377(9759):31-41.

28. Cuzick J, DeCensi A, Arun B, Brown PH, Castiglione M, Dunn B, et al. Preventive therapy for breast cancer: a consensus statement. Lancet Oncol. 2011;12(5):496-503.

29. Howe LR, Subbaramaiah K, Patel J, Masferrer JL, Deora A, Hudis $\mathrm{C}$, et al. Celecoxib, a selective cyclooxygenase 2 inhibitor, protects against human epidermal growth factor receptor 2 (HER-2)/neuinduced breast cancer. Cancer Res. 2002;62(19):5405-7.

30. Lanza-Jacoby S, Miller S, Flynn J, Gallatig K, Daskalakis C, Masferrer JL, et al. The cyclooxygenase-2 inhibitor, celecoxib, prevents the development of mammary tumors in Her-2/neu mice. Cancer Epidemiol Biomarkers Prev. 2003;12(12):1486-91.

31. Tran-Thanh D, Buttars S, Wen Y, Wilson C, Done SJ. Cyclooxygenase-2 inhibition for the prophylaxis and treatment of preinvasive breast cancer in a her- 2 /neu mouse model. Cancer Prev Res (Phila). 2010;3(2):202-11.

32. Brown PH, Subbaramaiah K, Salmon AP, Baker R, Newman RA, Yang P, et al. Combination chemoprevention of HER $2 /$ neu-induced breast cancer using a cyclooxygenase- 2 inhibitor and a retinoid $\mathrm{X}$ receptor-selective retinoid. Cancer Prev Res (Phila). 2008;1(3): 208-14.

33. Brandao R, Veeck J, Van de Vijver K, Lindsey P, de Vries B, van Elssen $\mathrm{C}$, et al. A randomised controlled phase II trial of preoperative celecoxib treatment reveals anti-tumour transcriptional response in primary breast cancer. Breast Cancer Res. 2013;15(2): R29.

34. El-Mir MY, Nogueira V, Fontaine E, Averet N, Rigoulet M, Leverve $X$. Dimethylbiguanide inhibits cell respiration via an indirect effect targeted on the respiratory chain complex I. J Biol Chem. 2000;275(1):223-8.

35. Owen MR, Doran E, Halestrap AP. Evidence that metformin exerts its anti-diabetic effects through inhibition of complex 1 of the mitochondrial respiratory chain. Biochem J. 2000;348(Pt 3): 607-14.
36. Quinn BJ, Kitagawa H, Memmott RM, Gills JJ, Dennis PA. Repositioning metformin for cancer prevention and treatment. Trends Endocrinol Metab. 2013;24(9):469-80.

37. Shaw RJ, Lamia KA, Vasquez D, Koo SH, Bardeesy N, Depinho $\mathrm{RA}$, et al. The kinase LKB1 mediates glucose homeostasis in liver and therapeutic effects of metformin. Science. 2005;310(5754): 1642-6.

38. Xue F, Michels KB. Diabetes, metabolic syndrome, and breast cancer: a review of the current evidence. Am J Clin Nutr. 2007;86(3):s823-835.

39. Bodmer M, Meier C, Krahenbuhl S, Jick SS, Meier CR. Long-term metformin use is associated with decreased risk of breast cancer. Diabetes Care. 2010;33(6):1304-8.

40. Bosco JL, Antonsen S, Sorensen HT, Pedersen L, Lash TL. Metformin and incident breast cancer among diabetic women: a population-based case-control study in Denmark. Cancer Epidemiol Biomarkers Prev. 2011;20(1):101-11.

41. Chlebowski RT, McTiernan A, Wactawski-Wende J, Manson JE, Aragaki AK, Rohan T, et al. Diabetes, metformin, and breast cancer in postmenopausal women. J Clin Oncol. 2012;30(23): 2844-52.

42. Goodwin PJ, Stambolic V, Lemieux J, Chen BE, Parulekar WR, Gelmon KA, et al. Evaluation of metformin in early breast cancer: a modification of the traditional paradigm for clinical testing of anti-cancer agents. Breast Cancer Res Treat. 2011;126(1):215-20.

43. He X, Esteva FJ, Ensor J, Hortobagyi GN, Lee MH, Yeung SC. Metformin and thiazolidinediones are associated with improved breast cancer-specific survival of diabetic women with HER2+ breast cancer. Ann Oncol. 2012;23(7):1771-80.

44. van Staa TP, Patel D, Gallagher AM, de Bruin ML. Glucoselowering agents and the patterns of risk for cancer: a study with the General Practice Research Database and secondary care data. Diabetologia. 2012;55(3):654-65.

45. Anisimov VN, Egormin PA, Piskunova TS, Popovich IG, Tyndyk ML, Yurova MN, et al. Metformin extends life span of HER-2/neu transgenic mice and in combination with melatonin inhibits growth of transplantable tumors in vivo. Cell Cycle. 2010;9(1):188-97.

46. Zhu P, Davis M, Blackwelder A, Bachman N, Liu B, Edgerton S, Williams LL, Thor AD, Yang X. Metformin Selectively Targets Tumor Initiating Cells in erbB-2 Overexpressing Breast Cancer Models. Cancer Prev Res (Phila) 2013.

47. Bonanni B, Puntoni M, Cazzaniga M, Pruneri G, Serrano D, Guerrieri-Gonzaga A, et al. Dual effect of metformin on breast cancer proliferation in a randomized presurgical trial. J Clin Oncol. 2012;30(21):2593-600.

48. Hadad S, Iwamoto T, Jordan L, Purdie C, Bray S, Baker L, et al. Evidence for biological effects of metformin in operable breast cancer: a pre-operative, window-of-opportunity, randomized trial. Breast Cancer Res Treat. 2011;128(3):783-94.

49. Niraula S, Dowling RJ, Ennis M, Chang MC, Done SJ, Hood N, et al. Metformin in early breast cancer: a prospective window of opportunity neoadjuvant study. Breast Cancer Res Treat. 2012;135(3):821-30.

50. Goodwin PJ, Pritchard KI, Ennis M, Clemons M, Graham M, Fantus IG. Insulin-lowering effects of metformin in women with early breast cancer. Clin Breast Cancer. 2008;8(6):501-5.

51. A Phase III Randomized Trial of Metformin Versus Placebo on Recurrence and Survival in Early Stage Breast Cancer. [ http:// clinicaltrials.gov/show/NCT01101438]

52. Phase II Randomized Study of Neoadjuvant Metformin Plus Letrozole vs Placebo Plus Letrozole for ER-positive Postmenopausal Breast Cancer [[http://clinicaltrials.gov/ct2/show/ NCT01589367?term $=$ han+metformin+breast\&rank=1]

53. A Phase 2 Single Arm Study to Examine the Effects of Metformin on Cancer Metabolism in Patients With Early Stage Breast Cancer 
Receiving Neoadjuvant Chemotherapy [http:/clinicaltrials.gov/ct2/ show/NCT01266486?term $=$ Harris + metformin+breast\&rank=1]

54. Phase II Pre-Surgical Intervention Study for Evaluating the Effect of Metformin on Breast Cancer Proliferation [http://clinicaltrials.gov/ ct $2 /$ show/NCT00930579?term=hershman+metformin+ breast\&rank $=1]$

55. Metformin Hydrochloride in Patients With Atypical Hyperplasia or In Situ Breast Cancer to Placebo in Decreasing Atypical Cells in Patients With Atypical Hyperplasia or in Situ Breast Cancer [http:// clinicaltrials.gov/ct2/show/record/NCT01905046?term=phase+III+ metformin+breast\&rank=2]

56. Tang X-H, Gudas LJ. Retinoids, Retinoic Acid Receptors, and Cancer. Ann Rev Pathol Mech Dis. 2011;6(1):345-64.

57. Mongan NP, Gudas LJ. Diverse actions of retinoid receptors in cancer prevention and treatment. Differentiation. 2007;75(9): 853-70.

58. Anzano MA, Byers SW, Smith JM, Peer CW, Mullen LT, Brown $\mathrm{CC}$, et al. Prevention of breast cancer in the rat with 9-cis-retinoic acid as a single agent and in combination with tamoxifen. Cancer Res. 1994;54(17):4614-7.

59. Moon RC, Thompson HJ, Becci PJ, Grubbs CJ, Gander RJ, Newton DL, et al. N-(4-Hydroxyphenyl)retinamide, a new retinoid for prevention of breast cancer in the rat. Cancer Res. 1979;39(4):1339-46.

60. Wu K, Kim HT, Rodriquez JL, Munoz-Medellin D, Mohsin SK, Hilsenbeck SG, et al. 9-cis-Retinoic acid suppresses mammary tumorigenesis in C3(1)-simian virus $40 \mathrm{~T}$ antigen-transgenic mice. Clin Cancer Res. 2000;6(9):3696-704.

61. Kong G, Kim HT, Wu K, DeNardo D, Hilsenbeck SG, Xu XC, et al. The retinoid X receptor-selective retinoid, LGD1069, downregulates cyclooxygenase- 2 expression in human breast cells through transcription factor crosstalk: implications for molecularbased chemoprevention. Cancer Res. 2005;65(8):3462-9.

62. Lee HY, Dawson MI, Walsh GL, Nesbitt JC, Eckert RL, Fuchs E, et al. Retinoic acid receptor- and retinoid $\mathrm{X}$ receptor-selective retinoids activate signaling pathways that converge on AP- 1 and inhibit squamous differentiation in human bronchial epithelial cells. Cell Growth Differ. 1996;7(8):997-1004.

63. Uray IP, Shen Q, Seo HS, Kim H, Lamph WW, Bissonnette RP, et al. Rexinoid-induced expression of IGFBP-6 requires RARbetadependent permissive cooperation of retinoid receptors and AP-1. J Biol Chem. 2009;284(1):345-53

64. Seewaldt VL, Kim JH, Caldwell LE, Johnson BS, Swisshelm K, Collins SJ. All-trans-retinoic acid mediates G1 arrest but not apoptosis of normal human mammary epithelial cells. Cell Growth Differ. 1997;8(6):631-41.

65. Wu K, DuPre E, Kim H, Tin UC, Bissonnette RP, Lamph WW, et al. Receptor-selective retinoids inhibit the growth of normal and malignant breast cells by inducing G1 cell cycle blockade. Breast Cancer Res Treat. 2006;96(2):147-57.

66. Yang L, Ostrowski J, Reczek P, Brown P. The retinoic acid receptor antagonist, BMS453, inhibits normal breast cell growth by inducing active TGFbeta and causing cell cycle arrest. Oncogene. 2001;20(55):8025-35.

67. Hong WK, Lippman SM, Itri LM, Karp DD, Lee JS, Byers RM, et al. Prevention of second primary tumors with isotretinoin in squamous-cell carcinoma of the head and neck. N Engl J Med. 1990;323(12):795-801.

68. Veronesi U, De Palo G, Marubini E, Costa A, Formelli F, Mariani L, et al. Randomized trial of fenretinide to prevent second breast malignancy in women with early breast cancer. J Natl Cancer Inst. 1999;91(21):1847-56.

69. Veronesi U, Mariani L, Decensi A, Formelli F, Camerini T, Miceli $\mathrm{R}$, et al. Fifteen-year results of a randomized phase III trial of fenretinide to prevent second breast cancer. Ann Oncol. 2006;17(7):1065-71.
70. Liby K, Risingsong R, Royce DB, Williams CR, Yore MM, Honda $\mathrm{T}$, et al. Prevention and treatment of experimental estrogen receptornegative mammary carcinogenesis by the synthetic triterpenoid CDDO-methyl Ester and the rexinoid LG100268. Clin Cancer Res. 2008;14(14):4556-63.

71. Medina D, Kittrell F, Hill J, Zhang Y, Hilsenbeck SG, Bissonette R, et al. Prevention of tumorigenesis in p53-null mammary epithelium by rexinoid bexarotene, tyrosine kinase inhibitor gefitinib, and celecoxib. Cancer Prev Res (Phila). 2009;2(2):168-74.

72. Woditschka S, Haag JD, Waller JL, Monson DM, Hitt AA, Brose HL, et al. Neu-induced retroviral rat mammary carcinogenesis: a novel chemoprevention model for both hormonally responsive and nonresponsive mammary carcinomas. Cancer Res. 2006;66(13): 6884-91.

73. Wu K, Kim HT, Rodriquez JL, Hilsenbeck SG, Mohsin SK, Xu XC, et al. Suppression of mammary tumorigenesis in transgenic mice by the RXR-selective retinoid, LGD1069. Cancer Epidemiol Biomarkers Prev. 2002;11(5):467-74.

74. Esteva FJ, Glaspy J, Baidas S, Laufman L, Hutchins L, Dickler M, et al. Multicenter phase II study of oral bexarotene for patients with metastatic breast cancer. J Clin Oncol. 2003;21(6):999-1006.

75. Brown PH, Arun B, Miller A, Isaacs C, Gutierrez C, et al.: Phase II trial of bexarotene in wormen at high risk of breast cancer, comparison of protein and RNA biomarkers. 7th Annual AACR International Frontiers in Cancer Prevention Research Meeting, Chicago, 2008: p 178-79 2008.

76. Grubbs CJ, Hill DL, Bland KI, Beenken SW, Lin TH, Eto I, et al. 9cUAB30, an RXR specific retinoid, and/or tamoxifen in the prevention of methylnitrosourea-induced mammary cancers. Cancer Lett. 2003;201(1):17-24.

77. Grubbs CJ, Lubet RA, Atigadda VR, Christov K, Deshpande AM, Tirmal V, et al. Efficacy of new retinoids in the prevention of mammary cancers and correlations with short-term biomarkers. Carcinogenesis. 2006;27(6):1232-9.

78. Li Y, Zhang Y, Hill J, Shen Q, Kim HT, Xu X, et al. The Rexinoid LG100268 prevents the development of preinvasive and invasive estrogen receptor negative tumors in MMTV-erbB2 mice. Clin Cancer Res. 2007;13(20):6224-31.

79. Mazumdar A, Medina D, Kittrell FS, Zhang Y, Hill JL, Edwards $\mathrm{DE}$, et al. The combination of tamoxifen and the rexinoid LG100268 prevents ER-positive and ER-negative mammary tumors in p53-null mammary gland mice. Cancer Prev Res (Phila). 2012;5(10):1195-202.

80. Ghosh-Choudhury N, Mandal CC, Ghosh Choudhury G. Simvastatin induces derepression of PTEN expression via NFkappaB to inhibit breast cancer cell growth. Cell Signal. 2010;22(5):749-58.

81. Jacobs EJ, Newton CC, Thun MJ, Gapstur SM. Long-term use of cholesterol-lowering drugs and cancer incidence in a large United States cohort. Cancer Res. 2011;71(5):1763-71.

82. Mandal CC, Ghosh-Choudhury N, Yoneda T, Choudhury GG. Simvastatin prevents skeletal metastasis of breast cancer by an antagonistic interplay between p53 and CD44. J Biol Chem. 2011;286(13):11314-27.

83. Vinogradova Y, Coupland C, Hippisley-Cox J. Exposure to statins and risk of common cancers: a series of nested case-control studies. BMC Cancer. 2011;11:409.

84. Friis S, Poulsen AH, Johnsen SP, McLaughlin JK, Fryzek JP, Dalton SO, et al. Cancer risk among statin users: a population-based cohort study. Int J Cancer. 2005;114(4):643-7.

85. Farwell WR, Scranton RE, Lawler EV, Lew RA, Brophy MT, Fiore LD, et al. The association between statins and cancer incidence in a veterans population. J Natl Cancer Inst. 2008;100(2):134-9.

86. Cauley JA, McTiernan A, Rodabough RJ, LaCroix A, Bauer DC, Margolis KL, et al. Statin use and breast cancer: prospective results 
from the Women's Health Initiative. J Natl Cancer Inst. 2006;98(10):700-7.

87. Ahern TP, Pedersen L, Tarp M, Cronin-Fenton DP, Garne JP, Silliman RA, et al. Statin prescriptions and breast cancer recurrence risk: a Danish nationwide prospective cohort study. J Natl Cancer Inst. 2011;103(19):1461-8.

88. Coogan PF, Rosenberg L, Palmer JR, Strom BL, Zauber AG, Shapiro S. Statin use and the risk of breast and prostate cancer. Epidemiology. 2002;13(3):262-7.

89. Undela K, Srikanth V, Bansal D. Statin use and risk of breast cancer: a meta-analysis of observational studies. Breast Cancer Res Treat. 2012;135(1):261-9.

90. Bonovas S, Filioussi K, Tsavaris N, Sitaras NM. Use of statins and breast cancer: a meta-analysis of seven randomized clinical trials and nine observational studies. J Clin Oncol. 2005;23(34):8606-12.

91. Nickels S, Vrieling A, Seibold P, Heinz J, Obi N, Flesch-Janys D, et al. Mortality and recurrence risk in relation to the use of lipidlowering drugs in a prospective breast cancer patient cohort. PLoS One. 2013;8(9):e75088.

92. Higgins MJ, Prowell TM, Blackford AL, Byrne C, Khouri NF, Slater SA, et al. A short-term biomarker modulation study of simvastatin in women at increased risk of a new breast cancer. Breast Cancer Res Treat. 2012;131(3):915-24.

93. Garwood ER, Kumar AS, Baehner FL, Moore DH, Au A, Hylton N, et al. Fluvastatin reduces proliferation and increases apoptosis in women with high grade breast cancer. Breast Cancer Res Treat. 2010;119(1):137-44.

94. Vinayak S, Schwartz EJ, Jensen K, Lipson J, Alli E, McPherson L, et al. A clinical trial of lovastatin for modification of biomarkers associated with breast cancer risk. Breast Cancer Res Treat. 2013;142(2):389-98.

95. Weil MK, Chen AP. PARP inhibitor treatment in ovarian and breast cancer. Curr Probl Cancer. 2011;35(1):7-50.

96. Liby KT. Abstract 1078: The efficacy of the PARP inhibitors olaparib and veliparib for prevention of breast cancer in a mouse model of BRCA1 deficiency. Cancer Research 2013, 73(8).

97. John EM, Miron A, Gong G, Phipps AI, Felberg A, Li FP, et al. Prevalence of pathogenic BRCA1 mutation carriers in 5 US racial/ ethnic groups. JAMA. 2007;298(24):2869-76.

98. Arcaro A. Targeting the insulin-like growth factor-1 receptor in human cancer. Front Pharmacol. 2013;4:30.

99. Jiang BH, Liu LZ. PI3K/PTEN signaling in angiogenesis and tumorigenesis. Adv Cancer Res. 2009;102:19-65.

100. Sabatini DM. mTOR and cancer: insights into a complex relationship. Nat Rev Cancer. 2006;6(9):729-34.

101. Liu M, Howes A, Lesperance J, Stallcup WB, Hauser CA, Kadoya $\mathrm{K}$, et al. Antitumor Activity of Rapamycin in a Transgenic Mouse Model of ErbB2-Dependent Human Breast Cancer. Cancer Res. 2005;65(12):5325-36.

102. Mercier I, Camacho J, Titchen K, Gonzales DM, Quann K, Bryant $\mathrm{KG}$, et al. Caveolin-1 and Accelerated Host Aging in the Breast Tumor Microenvironment: Chemoprevention with Rapamycin, an mTOR Inhibitor and Anti-Aging Drug. Am J Pathol. 2012;181(1):278-93.

103. Li Y-X, Himaya S, Kim S-K. Triterpenoids of Marine Origin as Anti-Cancer Agents. Molecules. 2013;18(7):7886-909.

104. Safe SH, Prather PL, Brents LK, Chadalapaka G, Jutooru I. Unifying mechanisms of action of the anticancer activities of triterpenoids and synthetic analogs. Anticancer Agents Med Chem. 2012;12(10):1211-20.

105. Kim EH, Deng C, Sporn MB, Royce DB, Risingsong R, Williams CR, et al. CDDO-methyl ester delays breast cancer development in BRCA1-mutated mice. Cancer Prev Res (Phila). 2012;5(1):89-97.

106. Uzoigwe J, Sauter ER. Cancer prevention and treatment using combination therapy with plant- and animal-derived compounds. Expert Rev Clin Pharmacol. 2012;5(6):701-9.

107. Crew KD, Brown P, Greenlee H, Bevers TB, Arun B, Hudis C, et al. Phase IB randomized, double-blinded, placebo-controlled, dose escalation study of polyphenon $\mathrm{E}$ in women with hormone receptor-negative breast cancer. Cancer Prev Res (Phila). 2012;5(9):1144-54.

108. Wright LE, Frye JB, Gorti B, Timmermann BN, Funk JL. Bioactivity of turmeric-derived curcuminoids and related metabolites in breast cancer. Curr Pharm Des 2013.

109. Samy RP, Gopalakrishnakone P, Ignacimuthu S. Anti-tumor promoting potential of luteolin against 7,12dimethylbenz(a)anthracene-induced mammary tumors in rats. Chem Biol Interact. 2006;164(1-2):1-14.

110. Eliassen AH, Hendrickson SJ, Brinton LA, Buring JE, Campos H, Dai Q, et al. Circulating carotenoids and risk of breast cancer: pooled analysis of eight prospective studies. J Natl Cancer Inst. 2012;104(24):1905-16.

111. Berquin IM, Edwards IJ, Chen YQ. Multi-targeted therapy of cancer by omega-3 fatty acids. Cancer Lett. 2008;269(2):363-77.

112. Castillo-Pichardo L, Cubano LA, Dharmawardhane S. Dietary grape polyphenol resveratrol increases mammary tumor growth and metastasis in immunocompromised mice. BMC Complement Altern Med. 2013;13:6.

113. Gomez LS, Zancan P, Marcondes MC, Ramos-Santos L, MeyerFernandes JR, Sola-Penna M, Da Silva D. Resveratrol decreases breast cancer cell viability and glucose metabolism by inhibiting 6phosphofructo-1-kinase. Biochimie 2013.

114. Khan MA, Chen HC, Wan XX, Tania M, Xu AH, Chen FZ, Zhang DZ. Regulatory effects of resveratrol on antioxidant enzymes: A mechanism of growth inhibition and apoptosis induction in cancer cells. Mol Cells 2013

115. Wada K, Nakamura K, Tamai Y, Tsuji M, Kawachi T, Hori A, et al. Soy isoflavone intake and breast cancer risk in Japan: from the Takayama study. Int J Cancer. 2013;133(4):952-60.

116. Xie Q, Chen ML, Qin Y, Zhang QY, Xu HX, Zhou Y, et al. Isoflavone consumption and risk of breast cancer: a dose-response meta-analysis of observational studies. Asia Pac J Clin Nutr. 2013;22(1):118-27.

117. Chiang KC, Yeh CN, Chen SC, Shen SC, Hsu JT, Yeh TS, et al. MART-10, a New Generation of Vitamin D Analog, Is More Potent than 1alpha,25-Dihydroxyvitamin $\mathrm{D}(3)$ in Inhibiting Cell Proliferation and Inducing Apoptosis in ER+MCF-7 Breast Cancer Cells. Evid Based Complement Alternat Med. 2012;2012:310872.

118. So JY, Smolarek AK, Salerno DM, Maehr H, Uskokovic M, Liu F, et al. Targeting CD44-STAT3 signaling by Gemini vitamin D analog leads to inhibition of invasion in basal-like breast cancer. PLoS One. 2013;8(1):e54020.

119. Vitamin D and Omega-3 Trial (VITAL) [http://clinicaltrials.gov/ show/NCT01169259]

120. Meads C, Ahmed I, Riley R. A systematic review of breast cancer incidence risk prediction models with meta-analysis of their performance. Breast Cancer Res Treat. 2012;132(2):365-77.

121. Catania C, Binder E, Cota D. mTORC1 signaling in energy balance and metabolic disease. Int J Obes. 2011;35(6):751-61.

122. Zoncu R, Efeyan A, Sabatini DM. mTOR: from growth signal integration to cancer, diabetes and ageing. Nat Rev Mol Cell Biol. 2011;12(1):21-35. 